\title{
Balancing of self-interests versus other- interests and five styles of conflict resolution
}

\author{
Bożena Kłusek-Wojciszke ${ }^{1, *}$, and Jacek Grodzicki ${ }^{1}$ \\ ${ }^{1}$ University of Gdańsk, Faculty of Economics, 119/121 Armii Krajowej St., 81-824 Sopot, Poland
}

\begin{abstract}
The classical analysis of conflict management assumes that there are 5 main styles of conflict resolution which originate from various combinations of attainment of the self-interest and other-interest. Cooperation is underlain by joint maximization of both interests, Competition means maximization of self-interest at the expense of otherinterest, Accommodation means maximization of other-interest at the expense of self-interest, Avoidance means neglect of both interests, while Compromise means a partial realization of the two interests. Although the five styles of conflict resolution are well-supported by empirical research, there is no research directly showing the assumed role of the two interests in the five styles of conflict resolution. The present paper presents an empirical study of 83 employees showing that the two interests (as measured by The Self- and Other Interest Inventory devised by Gerbasi \& Prentice) [1] are systematically and predictably related to the five styles of conflict resolution (as measured by the Questionnaire of Five Styles of Conflict Resolution devised by Kłusek) [2].
\end{abstract}

\section{Introduction}

Although the classical economy assumed that people are „natural egoists” and maximizing of self-interest is the sole criterion of rational hoice and behavior, much of recent research conducted by both behavioral economists and psychologists is inconsistent with this assumption. Self-interest is a strong human motivation, but is far from being the only one, as suggestested by at least three lines of empirical research.

The first line concerns resource (typically money) allocation between the self and strangers. Dictator and ultimatum games are the two most frequently used paradigms in this context. In the dictator game a participant is provided with a sum of money and asked to divide the sum between the self and a stranger also participating in the game. This decision is anonymous and irrevocable $[3,4]$. Of course, such a situation invites egoistic choices had people been pure egoists, they would have given themselves all the sum, giving no money to their partners at all. Actually, a meta-analysis of 150 studies performed on this topic revealed that on average people give $21 \%$ of the available money to a stranger and this decision does not depend on the amount of money involved [5]. The ultimatum game

* Corresponding author: b0505@op.pl 
ivolves a similar allocation decision, but the decision can be either accepted or vetoed by the other side. In the latter case, none of the participants receives any money [6]. This situation also invites egoistic choices, but clearly contained by expected egoism of the other side, as well as by the norm of equity. A summary of 97 studies employing the ultimatum game revealed that a majority of participants allocated the money equally and that the average amount of money allocated to the other side was $41 \%$. Moreover, most people rejected decisions which allotted them $20 \%$ of money or less, and this also did not depend on the absolute amount of money involved [5]. So, people strive not only to maximize their gain but also to obtain equity, even if this incurs a financial loss.

The second line of research showing that self-interest maximization is not the only human motive concerns behavior in morally relevant situations, such as cheating for financial gains. A classical study where people could cheat by reporting they solved tasks which had been actually insoluble, revealed that only less than $1 \%$ cheated in every trial to maximum gain [7]. Although most people cheated, they also did it only in 10-20\% of cases, presumably to have their cake and eat it too. That is, to gain financially from cheating but cheating to a small degree enabling them still to consider themselves as honest persons. Subsequent research has shown that people behave in more selfish and unethical ways in ambiguous situations which provide more room for justifying their immoral behavior [8,9].

The third line of studies showing that human motivation goes beyond self-iterests maximization concerns altruism or selfless (or even costly) acting for interests of others. Altruism is commonly observed in all cultures of the world and is frequently explained as a case of "enlightened egoism". According to this idea, altruistic behavior is rooted in self-interest but conceived in a long-term way, and based on reciprocity norm and expectation that others would return the received and benefit to the original helper. However, the last decade brought many findings showing that altruism is frequently spontaneous and void of such calculations of costs and benefits. A long series of studies on helping among toddlers seems to be especially persuasive $[10,11]$. When 18 -month-old children observe an adult failing to reach a dropped object (such as a clothespin) they spontaneously will get up and pick it for the adult in need. Most toddlers helped adults in a dozen of such situations and such helping behavior is typical also for chimpanzees, our closest kin in evolution. Obviously, such young children are unable to calculate possible long-term benefits of their altruism, or to follow moral norms or instructions, because they lack the necessary cognitive abilities to do so. So, these results provide a strong evidence for the idea that acting for others' interests is at least partially rooted in the human biological nature (although in later life socialization practices and adult moral norms play important role as well).

To summarize, people are able to act in a way which maximizes interests of both self and others. Although a sizeable minority of people assumes that self- and other-interests are inevitably antagonistic (a belief in life as a zero-sum game) [12], recent research suggests that the two interests are separate and mutually independent. For example Gerbasi and Prentice [1] devised an inventory measuring the propensity to act for the self- and otherinterest and showed that the two propensities are independent from each other and that in the prisoner dilemma situation persons scoring high on the self-interest scale maximize their own (but not their partners') gains, while persons scoring high on the other-interest scale maximize their partners' (but not their own) interests.

\section{Styles of conflict resolution}

Interestingly, the assumption of self- and other-interest independence lays at the core of the classical analyzes of interpersonal conflict and five main styles of conflict resolution competition, cooperation, avoidance, adjustment and compromise, as illustrated in Fig. 1. 
$[13,14]$. Numerous authors distinguish between the two interests, although use different names - self-interest is also called egoism, assertiveness or self-focus, while other-interest is also called altruism, collaboration, or focus on others.

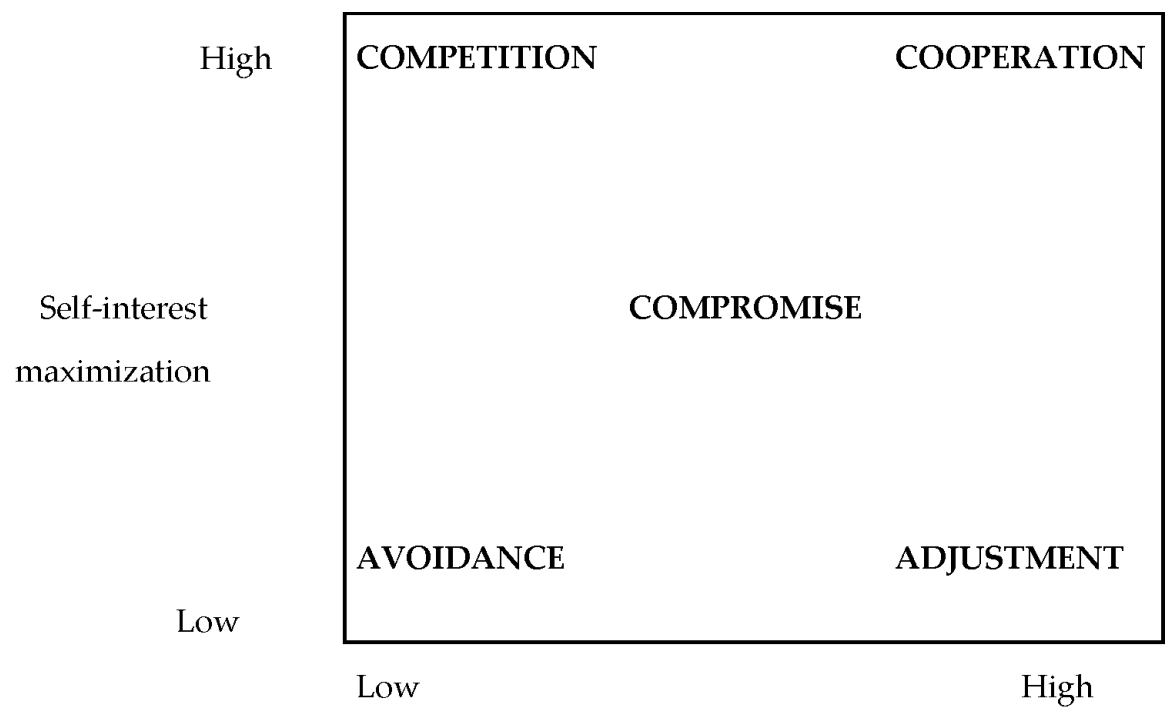

Other-interest maximization

Fig. 1. Five styles of conflict resolution based resulting from the independence of maximization of self-interest and other-interest as based on theorizing of Blake and Mounton [13] and Thomas [14].

Competition is a style of conflict resolution which involves self-interest maximization at the expense of other-interest which is minimized. Competition results from the assumption that a current situation has a zero-sum game nature and that winning by one side of a conflict is possible only when the other side is defeated. This style of conflict resolution increases own benefits but endangers the mere process of conflict resolution and frequently has adverse long-term consequences leading to deterioration of the relationship between the two sides of conflict [15]. Secondly, cooperation is a style involving maximization of both interests at the same time. This is the most fruitful style of conflict resolution bringing stable solutions and the greatest joint benefits for both parties and their relationship. Although beneficial, this style of conflict resolution is also hardest to implement because it requires accurate insights into the other side's point of view and needs, as well some distance toward own point of view. It also requires creativity in finding new solutions which would take into account both interests [16]. Third, adjustment is a style involving both maximization of other-interest and neglect of self-interest. This is typically applied when the longterm standing of a relationship between the conflicting sides is more imporatant than immediate results of a current conflict. This strategy is hard to implement (because it means abandonment of own interest) and dangerous (because it may lead to exploitation) [17]. Fourth, avoidance is a style involving abandonment of both self-interest and other-interest. This is delaying a solution rather than solving a conflict. It is typically applied when reaching a goal does not require negotiations [18]. Finally, compromise is a strategy involving partial realization of both interests, but also partial abandonment of each of them. This strategy leads to unstable consequences and is employed when relations between the conflicting sides are too strenuous to allow a satisfying agreement. 


\section{Interests and conflict resolution styles}

Clearly, this analysis implies that being driven by both self- and other-interest is a necessary precondition to versatile conflict resolution. If people had been driven solely by selfinterest they wold have been able to employ competition as the only behavioral style in a conflict situation. Of course, this would have disastrous consequences. However, the relations between the propensities to act for interests of self and others and preferred styles of conflict resolution have been only theoretically assumed rather than verified empirically. In the present study we offer an attempt in such verification. Specifically, we asked participating employees of different firms to fill questionnaires measuring propensities to act for selfand other-interest on one side and preferrences concerning the five styles of conflict resolution on the other side. We expected that the propensity to strive for self-interest would correlate positively with both styles located highly on the self-interest maximization dimension of Fig. 1., that is, competition and cooperation. By the same logic, we expected that the propensity to strive for other-interest would correlate positively with both styles located highly on the other-interest maximization dimension of Figure 1, that is, cooperation and adjustment. Because compromise is a style located in the middle of each dimension, it could be expected to correlate positively with each interest.

\section{The Present Study}

\subsection{Participants}

Eighty-three employees of different firms participated. Their mean age was $\mathrm{M}=31,73$ (SD $=10,82), 40$ were women, 25 were men, and 18 persons did not reveal their gender; 26 were rank-and-file employees, 17 were specialists, 21 were supervisors, and 19 persons did not reveal their position.

\subsection{Measures}

Two questionnaires were used in this study. The first was The Self- and Other-Interest Inventory devised Margaret Gerbasi and Deborah Prentice [1] from Princeton University, preadapted for the Polish language in our previous research. This inventory consists of The Self-Interest Scale comprising 9 items capturing the intensity of striving for self-intersts (e.g. I am constantly looking for ways to get ahead. I keep an eye out for my interests. Success is important to me.). The Other-interest Scale contains another 9 items concerning the intensity of striving for interests of other people (e.g. I am constantly looking for ways for my acquaintances to get ahead. I keep an eye out for other's interests. The success of my friends is important to me.). Participants show their agreement or disagreement with each item on a scale ranging from 1 (definitely disagree) to 5 (definitely agree). The reliabilities of both scaeles estimated with Cronbach's alpha appeared satisfactory: .85 for the selfinterest scale and .80 for the other-interest scale.

The second instrument was The Questionnaire of Five Styles of Conflict Resolution devised by Bożena Kłusek [2]. This questionnaire consists of 50 items concerning five styles of conflict resulution with 10 items per each style. The styles are: cooperation (e.g. I try to solve problems of both sides of the conflict. I reveal my opinins to the other side and ask them to do same.); competition (e.g. I am tenacious in getting it all my own way. When a matter is important, I am trying to win at all costs.); adjustment (I scarify my interests for to the iterests of the other side. I try to take the other's interests into account); avoidance (I try 
to delay the whole matter until there is enough of time to think it through. I put solving the problem off.), and compromise (I propose a solution partially stisfying both sides of conflict. I am looking for a solution which would be acceptable for both sides.). Participants declared how frequently they acted in a way described in consequent items on a scale: never (1), rarely (2), sometimes (3), frequently (4), and always (5). Reliabilities of all five scales appeared satisfactory in the present research: competition $(\alpha=.82)$, competition $(\alpha=$ $.87)$, adjustment $(\alpha=.81)$, avoidance $(\alpha=.88)$, and compromise $(\alpha=.80)$.

\section{Results}

We analyzed the data in two ways. First, we computed Pearson's r correlations between the two interests and each of the five styles of conflict resolution. As can be seen in Table 1, the self-interest correlated significantly with cooperation $(r=.26)$, competition $(r=.37)$, and compromise $(\mathrm{r}=.35)$, that is, with all styles involving maximization of self-interests in conflict situatuions. This is in line with theoretical expectations, the more so, that similar correlations did not emerge for adjustment $(r=.12)$ nor avoidance $(r=.16)$, the two styles involving abandonment of self-interest.

We expected the other-interest to correlate positively with the propensity to cooperate, adjust and compromise (the styles involving care about interests of others), but negatively with competition (i.e. the style involving actions against interests of others). Out of these expected correlations, only the relation between other-interest and cooperation appeared significant $(\mathrm{r}=.33)$. Unexpectedly, the correlation between other-interest and competition appeared positive $(\mathrm{r}=.36)$. This paradoxical correlation may be an effect of a positive relation between the two interests, which emerges and increases with age, as shown by Gerbasi and Prentice [1]. The authors expected such an age-related pattern because young people are independent of each other (so there is no correlation between the two interests), while adult people have more social responsibilities and beome more interdependent on each other (so the two interests become positively related). The present study involved adults and the correlation between the self-interest and other-interest appeared guite large $(\mathrm{r}=$ .54 ), which rises a possibility that the positive correlation of other-interest and competition is spurious and results from the substantial correlation between the two interests in the present sample. To check for this possibility, we computed a partial correlation between the self-interest and competition statistically controlling for other-interests. This partial correlation appeared low, $\mathrm{r}_{\mathrm{p}}=.20$, and failed to reach statistical significance. In effect, the correlation between the self-interest and competition should be interpretd as spurious and resulting from the substantial correlation of the two interests.

Table 1. Pearson $r$ correlations between the two interests and five styles of conflict resolution.

\begin{tabular}{|l|l|l|}
\hline Style & Self-interest & Other-interest \\
\hline Cooperation & $.26^{*}$ & $.33^{* *}$ \\
Competition & $.37^{* *}$ & $.36^{* *}$ \\
Adjustment & .12 & .13 \\
Avoidance & .16 & -.05 \\
Compromise & $.35^{* *}$ & .13 \\
\hline \multicolumn{2}{|c}{${ }^{*} \mathrm{p}<.05, * * \mathrm{p}<.01$} \\
\hline
\end{tabular}

The sizeable correlation between self-interest and other-interest persuaded us to yet another way of analyzing the data, namely, to perform a series of linear regression analyzes with self- and other-interest serving as predictors and the five consecutive styles of conflict resolution serving as dependent variables. The advantage of regression analysis is an ability to show a specific input of each predictor (here: the self- and other-nterest) in explanation 
of a dependent variable (here: the consecutive conflict reolution styles). Table 2 presents results of these five regression analyzes. As can be seen in the first row of the table, otherinterest appeared the sole predictor of cooperation $(\beta=.26)$. The second row shows that self-interest was a sole predictor of competition $(\beta=.22)$. The adjustment was signifintly predicted by none of the interests. Finally, both avoidance $(\beta=.26)$ and compromise $(\beta=$ .40) were significantly predicted by self-interest but not by other-iterests.

Table 2. Results of regression analyzes with self- and other-interest as predictors and the five styles of conflict resolution as predicted variables.

\begin{tabular}{|l|c|c|c|c|}
\hline Style & $\begin{array}{c}\text { Self-interest } \\
(\beta)\end{array}$ & $\begin{array}{c}\text { Other-interest } \\
(\beta)\end{array}$ & $\begin{array}{c}\mathbf{F} \\
(\text { model })\end{array}$ & $\mathrm{R}^{2}$ \\
\hline Cooperation & .12 & $.26^{*}$ & $5.20^{* *}$ & .094 \\
Competition & $.25^{*}$ & $.22 \mathrm{a}$ & $8.10^{* *}$ & .149 \\
Adjustment & .16 & -.07 & $<1$ & .000 \\
Avoidance & $.26^{*}$ & -.19 & $<1$ & .028 \\
Compromise & $.40^{* *}$ & -.09 & $5.76^{* *}$ & .105 \\
\hline
\end{tabular}

a $\mathrm{p}<.10, * \mathrm{p}<.05, * * \mathrm{p}<.01$

To conclude, the intensity of striving for self-interest appeared a logical, and theoretically consistent predictor of all styles of conflit resolution. Striving for other-interest, however, predicted in an expected way only the propensity for cooperation but not other styles of conflict resolution. It should be added that in the present reseach the declared intensity of striving for self-interest appeared higher $(\mathrm{M}=4.05$; $\mathrm{SD}=0.59)$ than striving for otherinterests $(\mathrm{M}=3.73$; $\mathrm{SD}=0.52)$, and this difference was statistically significant as evidenced by a Student's $t$ test for for dependent variables, $t(82)=5.47, p<.001$. So, striving for self-interest is both stronger and more strongly related to other variables than striving for other-interests.

\section{Discussion}

Self-interest appeared a better predictor of conflict resolution styles than other-interest. This difference cannot be explained by a differential quality of the two interests measurement because both scales showed quite high and similar reliabilities. It stands to reason, that the difference may have resulted from the fact that when responding the self-interst scale and the styles of conflict resolution questionnaire people always thought about interests of the same person (i.e. their own interests), but when responding the other-interest scale and the questionnaire they thought about different persons. For example, they could think about friends when filling the other-interest scale but about their co-workers and supervisors when filling the styles questionnaire. This possibility could be pursued in next studies with an explicit manipulation of instructions about whom participants should think when filling the two inventories. Finally, it is possible that striving for self-interest is a stronger motive than striving for interest of other people, as suggested by the previously presented direct comparison of declarations concerning the two interests. If self-interest is a relatively stronger motive it may explain why it is more strongly related to conflict resolution styles than the other-interests motive.

Like every empirical study, the present investigation has some limitations. First, both the interests and conflict resolution styles were measured with self-report declarations, rather than objectively ascertained behavior. In effect, the data are potentially biased by such factors as the tendency acquiesce or to appear in a socially desirable way. A relatively small sample size is another limitation of the present study. Therefore it is advisable to replicate the present study with behavioral measures and a larger sample. 
As noticed in the introduction, the classic economy (and psychology as far as the behavioristic approach is concerned) assumed the self-interest maximization to be the sole human motive. Two decades of recent research of behavioral economy and psychology have shown persuasively that it is not the sole human motive, that people also strive for interests of others and pursue in their behavior values and social norms which are frequently discrepant with self-interests. Still, studies dicussed at the outset suggest that self-interest is a stronger motivational force than pursuing interests of others. The present research suggests that it remains true also for conflict resolution behaviors which seem to be more strongly influenced by the self- than other-interests.

\section{References}

1. M.E. Gerbasi, D.A.Prentice, J. of Person. \& Soc. Psych., 105, 495-514 (2013)

2. B. Kłusek, Czas. Psych., lipiec 2009, 119 - 141 (2009)

3. R. Forsythe, J.L. Horowitz, N.E. Savin, M. Sefton, G. \& Econ. B., 6, 347-369 (2009)

4. D. Kahneman, J.L. Knetsch, R.H. Thaler, J. Bus., 59, 285-299 (1986)

5. J.C. Tisserand, F. Cochard, J. Le Gallo, Altruistic or Strategic Considerations: A Meta-Analysis on the Ultimatum and Dictator Games (CRESE, Université de FrancheComté, Besançon, 2015)

6. W. Güth, R. Schmittberger, B.J. Schwarze, J. Econ. B. \& Org., 3, 367-388 (1982)

7. N. Mazar, O. Amir, D.J. Ariel, J. Mark. Res., 45, 633-644 (2008)

8. F. Gino, D.J. Ariely, Person. \& Soc. Psych., 102, 445-459 (2012)

9. S. Shalvi, J. Dana, M.J. Handgraaf, C.K.W. De Dreu, Org. B. \& Hum. Dec. Proc., 115, 181-190 (2011)

10. F. Warneken, Atlas hugged. The foundations of human altruism. In: K. Gray and J. Graham (Eds.) Atlas of moral psychology (The Guilford Press, New York, 2018)

11. F. Warneken, M. Tomasello, Sc., 311 (5765), 1301-1303 (2006)

12. J. Różycka-Tran, P. Boski, B. Wojciszke, J. Cross-Cult., Psych., 46, 525-548 (2015)

13. R. Blake, J.Mounton, Managing intergroup conflict in industry (Gulf Publishing, Houston, 1964)

14. K. Thomas, Conflict and negotiation processes in organizations. In: M.D. Dunette and L.M. Hough (Eds.) Handbook of industrial and organizational psychology. 2nd ed., 3, 651-717 (Conmsulting Psychologists Press., Palo Alto, CA, 1992)

15. R. Lewicki, A. Hiam, K. Olander, Pomyśl zanim powiesz (Wydawnictwo Amber, Warszawa, 1998)

16. G. Kennedy, Negocjacje (Business Press, Warszawa, 1999 )

17. W. Mastenbroek, Negocjowanie (PWN, Warszawa, 1996)

18. M.H. Bazerman, M.A. Neale, Negocjujac racjonalnie (Pracownia Wydawnicza PTP, Olsztyn, 1997) 